\title{
Does the Use of Asthma-Controller Medication in Accordance with Guidelines Reduce the Incidence of Acute Exacerbations and Healthcare Costs?
}

\author{
Suh-Young Lee, M.D., Ph.D. ${ }^{1,2,3}$, Kyungjoo Kim, M.S. , Yong Bum Park, M.D. ${ }^{5}$ and Kwang Ha Yoo, \\ M.D., Ph.D. ${ }^{6}$ (i) \\ ${ }^{1}$ Institute of Allergy and Clinical Immunology, Seoul National University Medical Research Center, Seoul, ${ }^{2}$ Division of \\ Allergy and Clinical Immunology, Seoul National University Hospital, Seoul, Republic of Korea, ${ }^{3}$ Department of Molecular \\ Microbiology and Immunology, Brown University, Providence, RI, USA, ${ }^{4}$ Division of Pulmonary, Allergy and Critical Care \\ Medicine, Department of Internal Medicine, Seoul St. Mary's Hospital, College of Medicine, The Catholic University of Korea, \\ Seoul, ${ }^{5}$ Division of Pulmonary, Allergy, and Critical Care Medicine, Department of Internal Medicine, Kangdong Sacred Heart \\ Hospital, Hallym University College of Medicine, Seoul, ${ }^{6}$ Department of Internal Medicine, Konkuk University School of \\ Medicine, Seoul, Republic of Korea
}

Background: In asthma, consistent control of chronic airway inflammation is crucial, and the use of asthma-controller medication has been emphasized. Our purpose in this study is to compare the incidence of acute exacerbation and healthcare costs related to the use of asthma-controller medication.

Methods: By using data collected by the National Health Insurance Review and Assessment Service, we compared one-year clinical outcomes and medical costs from July 2014 to June 2015 (follow-up period) between two groups of patients with asthma who received different prescriptions for recommended asthma-controller medication (inhaled corticosteroids or leukotriene receptor antagonists) at least once from July 2013 to June 2014 (assessment period).

Results: There were 51,757 patients who satisfied our inclusion criteria. Among them, 13,702 patients (26.5\%) were prescribed a recommended asthma-controller medication during the assessment period. In patients using a recommended asthma-controller medication, the frequency of acute exacerbations decreased in the follow-up period, from $2.7 \%$ to $1.1 \%$. The total medical costs of the controller group decreased during the follow-up period compared to the assessment period, from $\$ 3,772,692$ to $\$ 1,985,475$. Only $50.9 \%$ of patients in the controller group used healthcare services in the follow-up period, and the use of asthma-controller medication decreased in the follow-up period.

Conclusion: Overall, patients using a recommended asthma-controller medication showed decreased acute exacerbation and reduced total healthcare cost by half.

Keywords: Asthma; Disease Management; Health-Effect Assessment; Costs and Cost Analysis

Address for correspondence: Kwang Ha Yoo, M.D., Ph.D.

Division of Pulmonary and Critical Care Medicine, Department of Internal Medicine, Konkuk University Medical Center, Konkuk University School of Medicine, 120-1 Neungdong-ro, Gwangjin-gu, Seoul 05030, Republic of Korea

Phone: 82-2-2030-7173, Fax: 82-2-2030-5009, E-mail: khyou@kuh.ac.kr

Received: Jun. 24, 2021, Revised: Aug. 9, 2021, Accepted: Sep. 1, 2021, Published online: Sep. 3, 2021

(a) It is identical to the Creative Commons Attribution Non-Commercial License (http://creativecommons.org/licenses/by-nc/4.0/). 


\section{Introduction}

Asthma is a chronic inflammatory disease of airways, and the progression of airway inflammation leads to recurrent episodes of symptoms, such as wheezing, breathlessness, chest tightness, and cough ${ }^{1}$. Asthma control means to suppress airway inflammation continuously and to prevent any disturbances in daily life ${ }^{2,3}$. Risk factors for asthma exacerbation include a previous history of asthma exacerbation or steroid burst, decreased pulmonary function, and involuntary cessation of asthma-controller medications ${ }^{4,5}$. In asthma management, especially in high-risk patients, regular use of controller medications, such as inhaled corticosteroids (ICS) and leukotriene receptor antagonists (LTRAs), is recommended to prevent acute exacerbation. Regular use of controller medication can also reduce accompanying socioeconomic burden ${ }^{6-8}$. Nevertheless, current records about the use of ICS or LTRAs in asthma were far below the goals specified in international guidelines ${ }^{9}$. With this background, even patients who do not use required medications and have asthma symptoms are mistakenly considered to have 'difficult to treat asthma ${ }^{10}$.

Given this background, the Health Insurance Review and Assessment Service (HIRA) since 2013 has annually done qualitative assessments of asthma management provided by all medical institutions that care for asthma in South Korea ${ }^{11}$. Considering that there is limited research on the disease burden of asthma in South Korea, we aimed to investigate whether the use of asthma-controlling medication affects the frequency of acute exacerbation and subsequent healthcare costs by reviewing the results of qualitative assessment of asthma management.

\section{Materials and Methods}

\section{Data source}

The HIRA is an agency responsible for evaluating all medical claims data in South Korea, which has adopted a single mandatory government-established health-insurance system $^{12}$. Since 2013, the HIRA has done annual qualitative assessments of asthma management provided by all medical institutions that care for asthma in South Korea and has released the results of the qualitative assessment annually since January $2015^{13}$. The purposes of the HIRA qualitative assessment were to improve the control of asthma and to decrease social medical costs for asthma management. We collected and analyzed data in HIRA's database from all patients recorded with diagnostic codes J45-J46 according to the 10th International Statistical Classification of Disease and Related Health Problems (ICD-10). Patients were defined as having asthma when all of the following criteria were met: (1) They

A
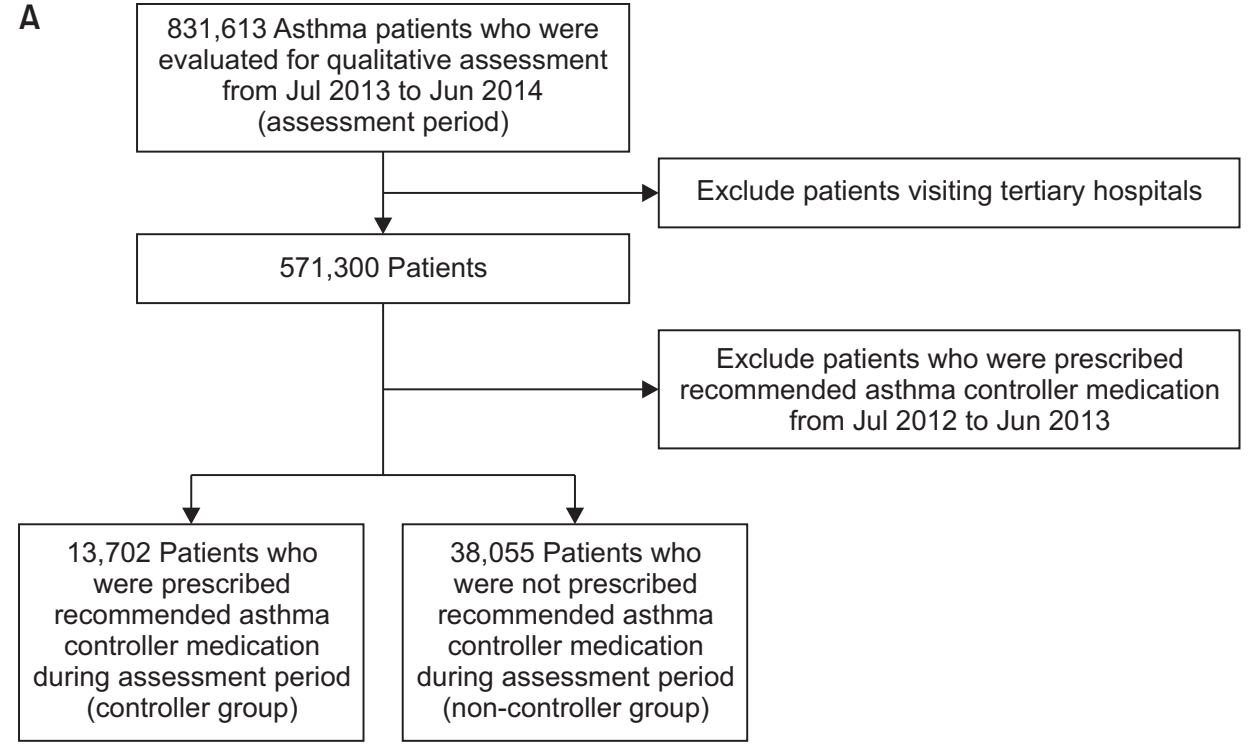

B

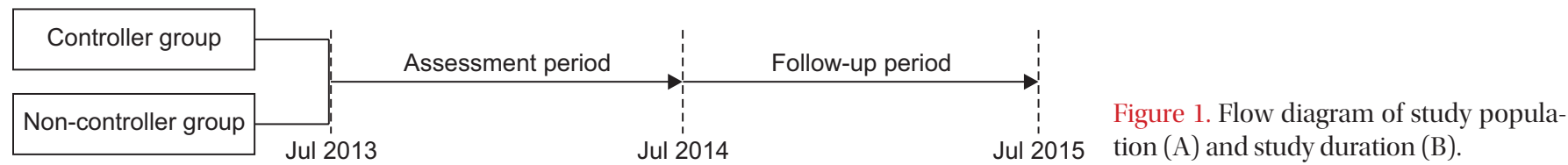


were older than 12 years on January 1, 2011; (2) They had received J45.x-J46.x as the principal diagnostic code or within the fifth position of secondary diagnostic codes; (3) They were prescribed any of the following asthma medications: ICS, ICS/ long-acting beta2-agonists (LABA), LTRA, short-acting beta2agonists (SABA), short-acting muscarinic antagonists (SAMA), SAMA+SABA, systemic steroids, methylxanthine, or systemic bronchodilators.

\section{Qualitative assessment for asthma management}

The appropriate management of asthma was assessed qualitatively by means of the following seven items: (1) performance rate of pulmonary function test, (2) percentage of visits to the same medical institution for asthma management, (3) prescription rate of ICS, (4) prescription rate of anti-inflammatory controllers for asthma, such as LTRAs and ICS, (5) prescription rate of LABA without ICS, (6) prescription rate of SABA without ICS, and (7) prescription rate of oral corticosteroids (OCS) without ICS.

Among these seven items, the items numbered 1 to 4 were sub-categorized as mandatory.

\section{Study subjects}

We evaluated 831,613 asthma patients from 16,804 institutions in South Korea for the qualitative assessment of asthma management (Figure 1A). We conducted the assessment using data collected by HIRA from July 2013 to June 2014 (assessment period). To exclude the effect of treatment before the assessment period, we included only patients who had visited primary or secondary hospitals but had not been prescribed a recommended asthma-controller medication (ICS, or LTRAs) for a year prior to the assessment period.

We divided the study subjects into two groups; patients who were prescribed recommended asthma-controller medication at least once during the assessment period (controller group), and patients who had not been prescribed such a medication (non-controller group) during the assessment period. By collecting and reviewing healthcare-visit claims data during the study period (1-year assessment period, from July 2013 to June 2014, followed by a one-year follow-up period from July 2014 to June 2015) (Figure 1B) retrospectively, we compared clinical outcomes, direct costs, including outpatient and inpatient service (including emergency room and intensive care unit) use and cost of medications for all diseases with diag-

Table 1. Demographics of asthma patients with and without recommended asthma-controller medications (2013 Jul-2014 Jun)

\begin{tabular}{|lccc|}
\hline & Controller group (n=13,702) & Non-controller group (n=38,055) & p-value \\
\hline Age, yr & $61.8 \pm 16.5$ & $64.0 \pm 16.2$ & $<0.001$ \\
\hline Male sex & $5,464(39.9)$ & $16,028(42.1)$ & $<0.001$ \\
\hline Composition of hospital & & & \\
\hline Secondary hospitals & $1,854(13.5)$ & $2,453(6.4)$ & $<0.001$ \\
\hline Clinics & $13,050(95.2)$ & $36,306(95.4)$ & 0.438 \\
\hline Physical specialty & & & $<1,541(82.9)$ \\
\hline Internal Medicine & $12,068(88.1)$ & $14,547(38.2)$ & $<0.001$ \\
\hline Others & $6,402(46.7)$ & & 0.001 \\
\hline Type of insurance coverage & & $34,762(91.3)$ & $<0.001$ \\
\hline Medical insurance & $12,490(91.2)$ & $3,293(8.7)$ & $7.2 \pm 8.7$ \\
\hline Medical care & $1,212(8.8)$ & & - \\
\hline OPD visits & $8.1 \pm 8.8$ & & - \\
\hline Medication use & & & - \\
\hline ICS & $2,683(19.6)$ & & - \\
\hline ICS/LABA & $3,502(25.6)$ & & - \\
\hline LTRA & $10,404(75.9)$ & & - \\
\hline Amount of used medication & & & \\
\hline ICS (No. of inhalant) & $3.7 \pm 4.8$ & & \\
\hline ICS/LABA (No. of inhalant) & $1.9 \pm 1.6$ & & \\
\hline LTRA, day & $35.9 \pm 62.7$ & & \\
\hline
\end{tabular}

Values are presented as mean \pm SD or number (\%).

OPD: outpatient department; ICS: inhaled corticosteroid; LABA: long-acting beta2-agonists; LTRA: leukotriene antagonist. 
nostic codes J45-J46. We defined acute asthma exacerbation as being when the patient visited the emergency room or was admitted to the hospital (general ward or intensive care unit) with diagnostic code J45.X-J46.X, or when asthma medication was prescribed to the patient.

\section{Ethical issues}

This study was approved by the Institutional Review Board of the Catholic University of Korea, Seoul St. Mary's Hospital (No. KC16RESI0560). Requirement for informed consent was waived because the study was retrospective.

\section{Statistics}

We used the Student t-test for continuous variables and the chi-square test for categorical variables and did all statistical analyses using SAS version 9.2 (SAS Institute Inc., Cary NC, USA).

\section{Results}

We included 51,757 patients who met the criteria in this study. Among them, 13,702 patients (26.5\%) were prescribed a recommended asthma-controller medication during the assessment period (controller group). The remaining 38,055 patients were classified into the non-controller group.

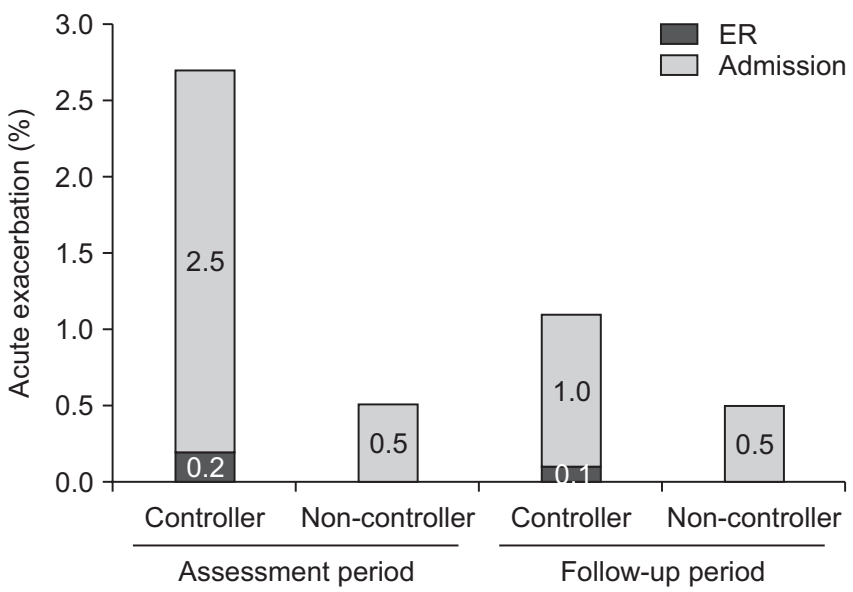

Figure 2. The frequency of acute exacerbation was decreased in the follow-up period from that in the assessment period in the controller group (2.7\% to $1.1 \%$ ), although there was no difference between the assessment period and the follow-up period in the non-controller group ( $0.5 \%$ to $0.5 \%)$. ER: emergency room.

\section{Demographics of patients with asthma in the controller and non-controller groups}

The median age of patients in the controller group was lower than that of the non-controller group during the assessment period $(61.8 \pm 16.5$ vs. $64.0 \pm 16.2, \mathrm{p}=0.001)$, and the proportion of male patients was lower in the controller group (39.9\% vs. $42.1 \%, \mathrm{p}=0.001$ ) (Table 1 ). More patients were treated in secondary hospitals in the controller group than in the non-controller group ( $13.5 \%$ vs. $6.4 \%, \mathrm{p}=0.001$ ). For most of the patients, medical expenses were covered by medical insurance, and the rates were not significantly different between the two groups (91.2\% vs. $91.3 \%, \mathrm{p}=0.494)$. The mean number of outpatient visits was higher in the controller group (8.1 \pm 8.8 vs. $7.2 \pm 8.7, \mathrm{p}<0.001)$. In the controller group, the mean usage of ICS, ICS/LABA, and LTRAs for a year was $3.7 \pm 4.8$ inhalers, $1.9 \pm 1.6$ inhalers, and $35.9 \pm 62.7$ tablets, respectively.

\section{Acute exacerbation of asthma during the assessment and follow-up periods}

The frequency of acute exacerbation was higher in the controller group than in the non-controller group in both the assessment and the follow-up periods $(2.7 \%$ vs. $0.5 \%, 1.1 \%$ vs. $0.5 \%$ ) (Figure 2). However, the rate of acute exacerbation decreased from $2.7 \%$ in the assessment period to $1.1 \%$ in the follow-up period in the controller group. In the non-controller group, there was no change in the rate of acute exacerbation during the follow-up period.

\section{Changes of total healthcare cost and asthma medication use in the controller group}

Only 50.9\% (n=6,970) among 13,702 patients in the controller group used healthcare services in the year following the

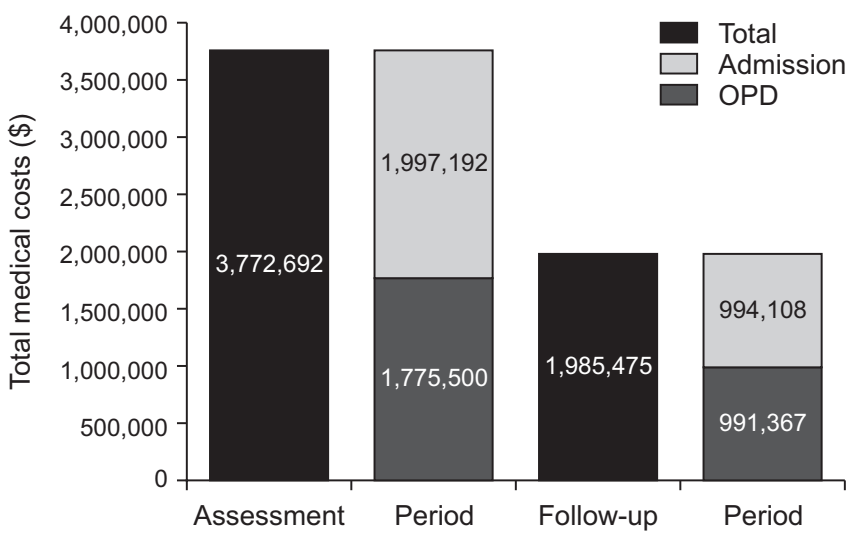

Figure 3. The total medical costs of the controller group decreased in the follow-up period from what it was in the assessment period $(\$ 3,772,692$ to $\$ 1,985,475)$. OPD: outpatient department. 
assessment period. As a result, the total medical costs of the controller group decreased in the follow-up period from what they had been during the assessment period (from \$3,772,692 to $\$ 1,985,475$ ) (Figure 3 ). Because $49.1 \%$ of the patients in the controller group did not use healthcare services after the assessment period, the total number of medication users decreased. Even in healthcare users, the use of both ICS-containing inhalers and LTRAs decreased during the follow-up period. The use of both SABA without ICS and OCS without ICS slightly increased. After the assessment period, laboratory tests, such as chest radiography and pulmonary function tests, were done less often (Figure 4).

\section{Discussion}

Our purpose in this large retrospective population study was to characterize the features of asthma management in South Korea and to measure the frequency of acute exacerbations during the asthma qualitative assessment period in terms of the use of asthma-controller medication using the South Korean national database from HIRA. Among 51,757 patients included, $26.5 \%$ were prescribed a recommended asthma-controller medication during the assessment period. In patients with asthma-controller medication, the frequency of acute exacerbations and total medical costs decreased in the follow-up period from what they had been in the assessment period.

This is the first study to compare medical cost and the frequency of asthma exacerbation using the results of a national qualitative assessment on asthma management. Because asthma-controller medications are effective in preventing acute exacerbations ${ }^{14-16}$ and reduction of medical resources $^{17-24}$, long-term treatment with controller medication is warranted in asthma management. On this basis, we did the qualitative assessment of asthma management in South Korea. By using the national health insurance claims data, we could investigate all subjects treated with asthma during the study period and obtained accurate medical information on a large number of subjects.

However, the following issues should be considered in interpreting our results. First, information on the baseline asthma severity of both groups was not defined in this study, because of the limitations of the data source. This limitation could imply selection bias, in that high-risk patients are more likely to use asthma-controller medication than are low-risk patients. To compensate for this limitation, we excluded patients who had visited tertiary hospitals or were prescribed controller medication before the assessment period. These strategies could indirectly correct the difference in severity between groups by excluding severe patients. Next, a direct comparison of total medical costs between groups was not available, because of loss of patients in the follow-up period. If the former comparison is satisfied, the use of controller medication to reduce medical costs will become a practice that is more evidence-based. Third, we aimed only to describe the trend of outcomes during two periods, and did not do statistical analysis of the repeated outcome measures. Finally, we should consider that the prescribing behavior of individual doctors affects controller use and that individual adherence to prescribed medication differs between patients.

Poor adherence and discontinuation of asthma treatment without visiting doctors have been raised as issues where asthma is not controlled properly by asthma specialists. According to a report from a survey conducted in eight areas in the Asia-Pacific region ${ }^{9}$, only $18.2 \%$ of those with severe persistent asthma reported current use of an ICS compared with $12.0 \%$ of those with mild intermittent asthma, and $60.5 \%$ of respondents with severe persistent asthma reported current quick-acting bronchodilator use. According to a report that analyzed data from the Taiwan Health Insurance Database ${ }^{15}$, physicians in district hospitals and primary-care clinics were especially less likely to prescribe inhalers, including ICS, than were asthma specialists or physicians in medical centers. In

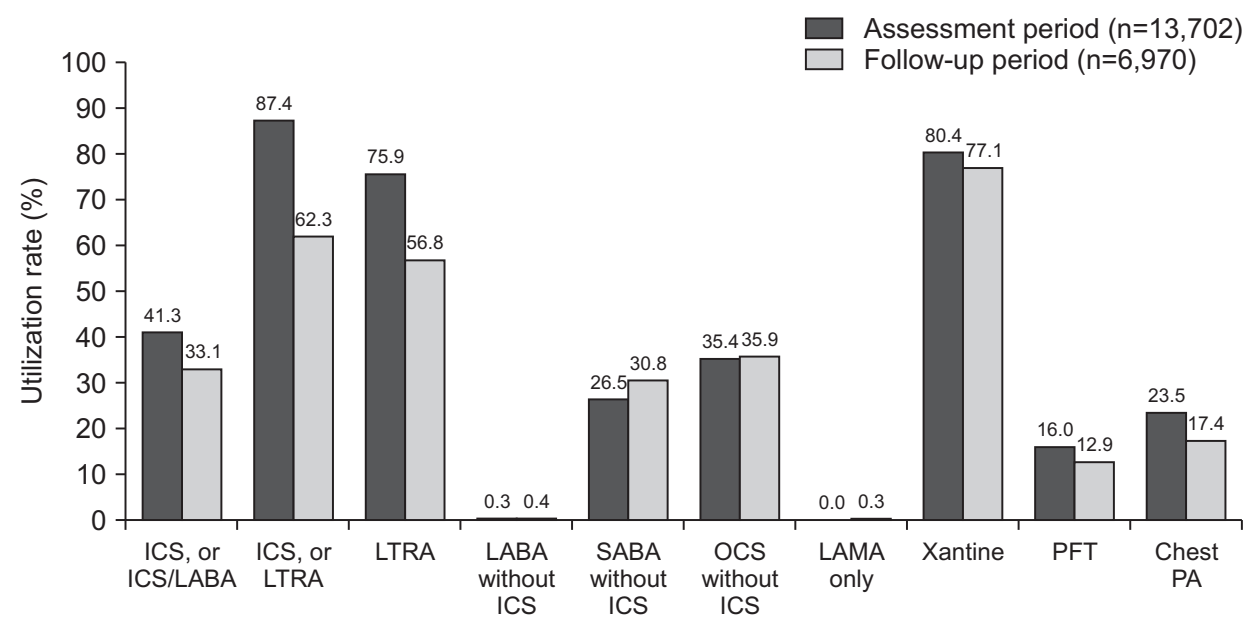

Figure 4. The use of both ICS-containing inhalers and LTRAs decreased in the follow-up period. ICS: inhaled corticosteroid; LABA: long-acting beta2agonists; LTRA: leukotriene antagonist; SABA: short-acting beta2-agonists; OCS: oral corticosteroid; LAMA: long-acting muscarinic antagonists; PFT: pulmonary function test; PA: posteroanterior. 
this study as well, about $50 \%$ of patients treated with a controller in the assessment period were missed in the follow-up year, perhaps because the patients had not visited a hospital if they had no worsening of symptoms even without controller medication. Somewhat lower asthma severity of enrolled patients may affect this outcome, and comprehensive consideration will be needed with a further longitudinal study on the effectiveness of as-needed treatment in mild asthma patients.

Through this study, we were able to analyze the characteristics of asthma treatment in Korea. Still, many patients were not using the recommended asthma-controller medication. Given the chronic nature of asthma and the need for longterm follow-up and management for a favorable prognosis, nationwide long-term educational strategies for asthma management are warranted.

\section{Authors' Contributions}

Conceptualization: Lee SY, Park YB, Yoo KH. Methodology: Lee SY, Kim K, Park YB, Yoo KH. Software: Kim K. Validation: Kim K. Formal analysis: Kim K. Data curation: Lee SY, Kim K. Writing - original draft preparation: Lee SY. Writing - review and editing: Lee SY, Park YB, Yoo KH. Approval of final manuscript: all authors.

\section{Conflicts of Interest}

No potential conflict of interest relevant to this article was reported.

\section{Funding}

This study was supported by HIRA (Join Project on Quality Assessment Research).

\section{References}

1. Bousquet J, Jeffery PK, Busse WW, Johnson M, Vignola AM. Asthma: from bronchoconstriction to airways inflammation and remodeling. Am J Respir Crit Care Med 2000;161:172045.

2. Chung KF, Godard P, Adelroth E, Ayres J, Barnes N, Barnes P, et al. Difficult/therapy-resistant asthma: the need for an integrated approach to define clinical phenotypes, evaluate risk factors, understand pathophysiology and find novel therapies. ERS Task Force on Difficult/Therapy-Resistant Asthma. European Respiratory Society. Eur Respir J 1999;13:1 198-208.

3. Frey U. Predicting asthma control and exacerbations: chronic asthma as a complex dynamic model. Curr Opin Allergy Clin
Immunol 2007;7:223-30.

4. DiMango E, Rogers L, Reibman J, Gerald LB, Brown M, Sugar EA, et al. Risk factors for asthma exacerbation and treatment failure in adults and adolescents with well-controlled asthma during continuation and step-down therapy. Ann Am Thorac Soc 2018;15:955-61.

5. Kang HR, Song HJ, Nam JH, Hong SH, Yang SY, Ju S, et al. Risk factors of asthma exacerbation based on asthma severity: a nationwide population-based observational study in South Korea. BMJ Open 2018;8:e020825.

6. Selroos O, Pietinalho A, Lofroos AB, Riska H. Effect of early vs late intervention with inhaled corticosteroids in asthma. Chest 1995;108:1228-34.

7. Drazen JM, Israel E, O'Byrne PM. Treatment of asthma with drugs modifying the leukotriene pathway. N Engl J Med 1999;340:197-206.

8. Kim DK, Park YB, Oh YM, Jung KS, Yoo JH, Yoo KH, et al. Korean Asthma Guideline 2014: summary of major updates to the Korean asthma guideline 2014. Tuberc Respir Dis 2016;79:111-20.

9. Lai CK, De Guia TS, Kim YY, Kuo SH, Mukhopadhyay A, Soriano JB, et al. Asthma control in the Asia-Pacific region: the asthma insights and reality in Asia-Pacific study. J Allergy Clin Immunol 2003;111:263-8.

10. Hedlin G, Bush A, Lodrup Carlsen K, Wennergren G, De Benedictis FM, Melen E, et al. Problematic severe asthma in children, not one problem but many: a GA2LEN initiative. Eur Respir J 2010;36:196-201.

11. Kim SR, Lee YC, Sung MJ, Bae HW. Current epidemiological data on asthma management in South Korea from qualitative assessment of asthma management by Health Insurance Review and Assessment Service (HIRA). Tuberc Respir Dis 2017;80:221-5.

12. Kim JA, Yoon S, Kim LY, Kim DS. Towards actualizing the value potential of Korea Health Insurance Review and Assessment (HIRA) data as a resource for health research: strengths, limitations, applications, and strategies for optimal use of HIRA data. J Korean Med Sci 2017;32:718-28.

13. van de Veen W, Wirz OF, Globinska A, Akdis M. Novel mechanisms in immune tolerance to allergens during natural allergen exposure and allergen-specific immunotherapy. Curr Opin Immunol 2017;48:74-81.

14. Makhinova T, Barner JC, Richards KM, Rascati KL. Asthma controller medication adherence, risk of exacerbation, and use of rescue agents among Texas medicaid patients with persistent asthma. J Manag Care Spec Pharm 2015;21:112432.

15. Chou CL, Perng DW, Lin TL, Lin AM, Chen TJ, Wu MS, et al. Analysis of prescription pattern and guideline adherence in the management of asthma among medical institutions and physician specialties in Taiwan between 2000 and 2010. Clin Ther 2015;37:2275-85.

16. Laforest L, Licaj I, Devouassoux G, Chatte G, Belhassen M, 
Van Ganse E, et al. Relative exposure to controller therapy and asthma exacerbations: a validation study in community pharmacies. Pharmacoepidemiol Drug Saf 2014;23:958-64.

17. Dean BB, Calimlim BM, Kindermann SL, Khandker RK, Tinkelman D. The impact of uncontrolled asthma on absenteeism and health-related quality of life. J Asthma 2009;46:861-6.

18. Gold LS, Thompson P, Salvi S, Faruqi RA, Sullivan SD. Level of asthma control and health care utilization in Asia-Pacific countries. Respir Med 2014;108:271-7.

19. Meng YY, Babey SH, Hastert TA, Lombardi C, Brown ER. Uncontrolled asthma means missed work and school, emergency department visits for many Californians. Policy Brief UCLA Cent Health Policy Res 2008;(PB2008-2):1-8.

20. Barnes PJ, Jonsson B, Klim JB. The costs of asthma. Eur Respir J 1996;9:636-42.

21. Jacob C, Bechtel B, Engel S, Kardos P, Linder R, Braun S, et al.
Healthcare costs and resource utilization of asthma in Germany: a claims data analysis. Eur J Health Econ 2016;17:195201.

22. Sadatsafavi M, Rousseau R, Chen W, Zhang W, Lynd L, FitzGerald JM. The preventable burden of productivity loss due to suboptimal asthma control: a population-based study. Chest 2014;145:787-93.

23. Accordini S, Bugiani M, Arossa W, Gerzeli S, Marinoni A, Olivieri M, et al. Poor control increases the economic cost of asthma: a multicentre population-based study. Int Arch Allergy Immunol 2006;141:189-98.

24. Williams SA, Wagner S, Kannan H, Bolge SC. The association between asthma control and health care utilization, work productivity loss and health-related quality of life. J Occup Environ Med 2009;51:780-5. 